\title{
Financiamiento de la seguridad social en tiempo de crisis del empleo
}

\author{
Ángel Guillermo Ruiz Moreno
}

agruizm@ruizmoreno.com

Formado pela Faculdade de Direito-agoraLegal Divisão de Estudos da Universidade

de Guadalajara (U. de G.), onde para além da licenciatura em Direito concluiu estudos de pós-graduação, incluindo vários

Diploma em Direito Público, Direito

Societário e Direito Social. Ele estudou

na U. G., Mestre em Direito com um terminal principal em negociações coletivas de trabalho e Segurança Social.

Recebido em 18/01/2011

Aprovado em 02/09/2011

\section{Resumo}

En todo el mundo es notorio el problema financiero del servicio público de la seguridad social, debido al imparable incremento del desempleo, mismo que se ha agudizado por la crisis económica mundial, el que junto a las nuevas formas de producción y empleo, han trastocando las relaciones laborales tradicionales que por desgracia evolucionaron sin un efectivo control legal desde hace al menos tres décadas. Así, el desempleo y la desprotección social que le acompaña obligan a buscar

nuevas formas de financiamiento vía impuestos exclusivamente, para el eventual sostenimiento a futuro de la seguridad social. Esta investigación se basa en la experiencia profesional de 30 años del autor en esta compleja temática, habiendo utilizado los métodos histórico, empírico, inductivo y deductivo.

\section{Palabras-Clave}

Seguridad social. Crisis económica mundial.

Desempleo. 


\title{
Social Security funding in time of employment crisis*
}

\author{
Ángel Guillermo Ruiz Moreno
}

Abstract

Around the world, the social security funding problem is noteworthy due to the increase of unemployment, even exasperated by the world economic crisis, and together with new forms of production and employment it has transformed traditional labor relations that unfortunately have evolved without an effective control for at least three decade. So, unemployment and the lack of social protection that follows force to find new funding through taxes, solely, to support the future of social security. This investigation is based on the author's 30-year-experience in this complex subject, having used the historical, empirical, inductive and deductive methods

Key wods

Social security. World economic crisis. Employment.

* Ponencia en el «II Foro Mundial De Seguridad Social» - Cd. Del Cabo, SUDÁfRICA, Dic., 2010 . 


\section{Sumario}

1 Contexto general del problema abordado.

2 Razones generales de la propuesta efectuada.

3 La notoria ausencia de identidad de la seguridad social contemporánea.

4 La financiación de la seguridad social del futuro.

5 Propuestas básicas acerca del tema abordado. 


\section{Contexto general del problema abordado}

Si la seguridad social no existiera, habría qué inventarla.

Y si la que existe ahora no nos sirve como debería hacerlo, entonces habrá qué reinventarla.

Son innumerables los desafíos actuales y futuros que nos presenta el servicio público de la seguridad social en todo el planeta, en especial en los países y regiones geográficas con economías emergentes: la extensión de cobertura para universalizarla y mejorarla, la indispensable protección a los trabajadores migrantes, nuevas y complejas estructuras familiares que deben ser reconocidas como recipiendarias del servicio, el envejecimiento poblacional aunado a las variables sanitarias debido al incremento de enfermedades catastróficas, el impacto de una crisis económica que todo apunta durará más de lo esperado, el incontenible crecimiento exponencial del sector informal de la economía, y otros fenómenos socioeconómicos que nos muestran — dicho esto sin el ánimo de parecer catastrofistas - , un mundo al borde del colapso.

Alcanzar una seguridad social dinámica, gestionada eficazmente y proactiva, como lo propone la Asociación Internacional de la Seguridad Social (AISS), atraviesa entonces por el complicado tema de su sostenibilidad financiera. Porque si la cuantía de los recursos destinados a financiar la seguridad social debe ir siempre acorde al nivel de cobertura que brinda el sistema, y cada día es más compleja la cobertura de las contingencias socio-vitales protegidas, el tema de la financiación resulta crucial y no puede ser desatendido por ningún país, mucho menos ahora, inmersos como lo estamos en una crisis económica mundial de tan alto impacto y coste social que obliga a afrontar las desastrosas consecuencias provocadas por la escasez de empleo en el mercado de trabajo formal. No obstante, lo más nefasto no es el desempleo en sí — pese a los millones de parados del planeta sin posibilidad de ingresos-; acaso lo más inquietante es el enorme sufrimiento y la desesperanza que engendra éste fenómeno en la población, que inerme resiente sus perniciosos efectos y no sabe qué hacer ante tan inesperada situación.

Cómo generar efectivas políticas de pleno empleo es el mayor desafío que enfrentan a inicios de la segunda década del siglo XXI los gobernantes de cualquier país del orbe, sea éste grande o pequeño, rico o pobre. Reconozcámoslo al menos: el desempleo resentido no es un problema coyuntural sino estructural. Ante tan inquietante contexto obliga a abandonar viejos cartabones y cambiar paradigmas.

No guste o nola idea, la “deslaboralización” de la seguridad social es impostergable ante el avance incontenible del desempleo, un asunto que resulta clave para la eventual supervivencia de este magnífico servicio público. 


\section{Razones generales de la propuesta efectuada}

Los Informes Anuales de la Organización Internacional del Trabajo (OIT), desde inicios del siglo XXI muestran la tendencia irreversible del mundillo del trabajo; de que de cada 10 nuevas ocupaciones que se crean en el planeta, alrededor de 8 de ellas se generan en el mercado informal de trabajo y debido a ello la economía informal crece de manera exponencial y preocupante en todo el orbe. Estadísticamente esa es una verdad incontrovertible, un indicador mundial inobjetable de que las políticas de empleo son ya una falacia.

El desempleo es un reto impostergable qué atender por parte de todos los países, pues nadie escapa de esta dura realidad que se ha vuelto más evidente debido al impacto de la enorme crisis económica y financiera mundial de mediados de 2008, la que ha puesto contra la pared a muchos países que, a efecto de paliar sus perniciosos efectos, tienen ya en la mira a los fondos de la seguridad social; para empezar, han congelado las pensiones; luego, echarán mano de las reservas técnicas pensionarias, y tras de eso disminuirán los apoyos a los servicios médicos y de prestaciones sociales de las instituciones encargadas de brindar este servicio público. Olvidan o interesadamente fingen hacerlo, que cuando mejor funciona la seguridad social es precisamente en épocas de crisis, al ser un instrumento eficaz e invaluable de la política económica y social de todo Estado.

Al ser tan notorio el decaimiento del empleo formal —ése tipo de trabajo que la OIT prefiere llamarle empleo decente, que es de duración indefinida, con prestaciones legales completas y protección social incluida-, la idea gira ya no en torno a la creación de nuevos puestos de trabajo, sino que se enfoca a la preservación de los ya existentes, decrementando prestaciones. El poco trabajo que se crea es precario y de duración determinada.

Este fenómeno socioeconómico se ha agudizado de un tiempo a la fecha, hay qué decirlo, debido a las nuevas formas de producción en este mundo hiper-tecnologizado que han transformado el mundo del trabajo contemporáneo y la producción de bienes o servicios. Lamentablemente tan brusco cambio le ha ganado la partida a las normativas legales vigentes en materia laboral y de seguridad social, pues no han logrado regularle de manera efectiva y oportuna, demostrando en los hechos que la realidad es siempre más sabia que el Derecho.

Cierto, la aparición de sofisticadas figuras jurídicas sin efectivo control legal laboral —que son fruto del ingenio del ser humano y paradójicamente puestas al servicio del capital que actúa sin sentido humano-, apuntan siempre hacia una evidente tercerización laboral, es decir, a una "triangulación” simulada de obligaciones que en no pocas ocasiones constituyen un fraude a la legislación laboral y de 
seguridad social y a sus principios jurídicos rectores. Su uso indiscriminado impacta inevitablemente en la recaudación necesaria para el financiamiento de la seguridad social, pues su fin es ése: librar de todo tipo de obligaciones a los empleadores, recipiendarios directos del trabajo subordinado, difuminando las responsabilidades inherentes a tal situación jurídica.

El elenco de estas singulares formas de entender el trabajo contemporáneo es grande: desde el mítico outsourcing — surgido en Inglaterra a inicios de la década de los años ochenta del siglo XX_- pasando por el arrendamiento de servicios, la subcontratación laboral subterránea, el suministro de mano de obra temporal o permanente, el staff leaisng, el pay rolling, las cooperativas de trabajo asociado, la empresas pagadoras, el downsizing aplicado en extremo, el contrato de distribución o el franchising, y hasta llegar a lo más sofisticado y actual como lo es el crowdsourcing en donde al través de uso del Internet se convoca a muchedumbres anónimas para que aporten desde su ordenador personal ideas acerca de ciertos temas o asuntos, retribuyéndose económicamente la mejor pero sin que el resto obtenga pago salarial ni protección social—, han convertido a la nefasta costumbre de derivar responsabilidades a terceros empleadores de papel insolventes en moda, siendo éstas actividades altamente perniciosas que han cobrado ya carta de naturalización en el mercado de trabajo mundial y cuyos efectos son desastrosos para el financiamiento de la seguridad social.

Tales figuras jurídicas, de aparente naturaleza civil y/o mercantil pero con un notorio trasfondo laboral, son ideas geniales que utilizan para su provecho particular la híper-tecnología, buscando en el nuevo proceso productivo el producir más con menos en aras de posicionarse mejor globalmente.

Se busca a toda costa alcanzar una flexibilización laboral para escapar de la rigidez normativa laboral existente, sin que hasta ahora ningún país haya sido capaz de ponerle freno a esta actitud inhumana, en donde vuelven a aparecer algunas formas de esclavitud moderna que creímos superadas. La desregulación laboral es también un constante a lo largo y ancho del planeta. Al respecto, los Estados y hasta los propios organismos internacionales del empleo se muestran incapaces para regular de manera efectiva estas nuevas formas laborales por un sinfín de causas.

Con ser eso malo, no es lo peor. Lo verdaderamente grave es que tras el disfrazamiento del empleo subordinado, se haya permitido que la seguridad social forme parte de la negociaciones laborales (esto es: si se afilia o no el operario subordinado, si se paga o no este servicio que teóricamente es irrenunciable e inalienable). Se trata de una conducta nefasta que abusa sin piedad del estado de necesidad del trabajador que debiera ser perseguida y sancionada, hasta desterrarla para siempre. 
El punto crucial a observar es que las formas y los métodos de producción ban cambiado drásticamente, y lo que antes era hoy ya no es; de alguna manera pareciera que las reminiscencias del Taylorismo como organización laboral, o del Fordismo y su trabajo en serie, aún no terminan de desaparecer del todo de la mente de quienes piensan, por supuesto que sin razón, que las cosas continúan siendo como antaño. Empero, aquella célebre frase atribuida a Henry Ford: "para trabajar yo busco dos brazos, no un cerebro", de plano que no va más, y menos ahora en plena era del conocimiento.

Así las cosas, el empleo decente es prácticamente una falacia, o mejor todavía: una especie en peligro de extinción. Los mismos gobernantes pretendan ocultar esta realidad mundial a sus gobernados mediante "Programas de empleo" ilusorios, pues mucho del empleo que se crea es simple maquillaje para fines meramente estadísticos, un trabajo temporal y precario creado artificialmente por el propio Estado sin entender que esto no resuelve el problema de fondo sino que lo disfraza. Aunque suene extraño, no es al Estado a quien le toca crear fuentes empleo, sino generar las condiciones políticas, económicas, fiscales, administrativas y de buen entorno laboral entre los factores de la producción, necesarias para alentar la inversión productiva y la creación de empleo digno. $\mathrm{Y}$ para ello desde luego se requiere implementar reformas estructurales de largo aliento.

Considérese que ante la falta de empleo formal, se alienta la creación del trabajo informal y la auto-ocupación en el sector informal de la economía; un sector social que muy rara vez alcanza a proteger la seguridad social nacional pese a su innegable influencia en la economía. Hay países - Bolivia, es un buen ejemplo de ello- en donde la informalidad laboral alcanza hasta el $80 \%$, y naturalmente que este sector no está protegido por la seguridad social.

Las lecciones que los fenómenos políticos, sociales, económicos y laborales en este mundo hiper-tecnologizado nos han legado en los últimos años, obligan a que tomemos plena conciencia de la urgente necesidad de adoptar medidas drásticas de contención y búsqueda de soluciones a tan sentidas problemáticas sociales. Ello porque ha quedado perfectamente demostrado tras la colosal crisis financiera y económica mundial de 2008 — de alguna manera mayor al mítico "crack bursátil" de 1929—, que lo que uno haga afecta al otro, así sean éstos países, instituciones, empresas o individuos quienes actúen irracionalmente y con excesivos afanes de lucro, pues no vivimos en ínsulas sino en una "aldea global" como bien definiera al planeta Marshall Mc Luhan.

Guste o no la idea, también ha quedado plenamente demostrado que Adam Smith estaba equivocado en sus teorías económicas: Estado y Mercado persiguen fines muy distintos, y no es verdad que "la mano invisible del Mercado" (sic) fuese capaz de regularse a sí mismo eficazmente. Por lo tanto, compete al Estado regular al Mercado, aunque haciéndolo de manera prudente a fin de que su injerencia no impida 
el buen desarrollo del mismo ni intente suplirlo, pues el Estado productor de bienes y servicios en la práctica tampoco fue una buena idea debido al monopolio ejercido y a la enorme ineficiencia de gestión mostrada.

Tan ominoso escenario mundial nos obliga pues a la búsqueda de nuevas formas de financiamiento para la seguridad social contemporánea, desligadas del empleo formal, dándose pasos decisivos para impedir su eventual desfinanciamiento ante el inevitable impago de los típicos "aportes a la seguridad social" que provoca el desempleo y las nuevas formas laborales sin control legal efectivo. Es conveniente buscar nuevas fuentes de financiamiento alternativas a fin de preservar dicho sistema protector social. Sólo así evitaremos que se socaven de raíz los cimientos en que descansa este servicio público esencial para la población.

\section{La notoria ausencia de identidad de la seguridad social contemporánea}

Vistas las circunstancias, la pregunta pertinente a plantear es simple, y de su acertada respuesta dependerá en gran medida la solución al problema planteado: ¿Qué es hoy la seguridad social contemporánea del siglo XXI? Esa es la pregunta clave que debemos formularnos todos los segurólogos sociales del planeta.

La búsqueda de la gennina identidad de la seguridad social contemporánea es una tarea compleja que no debe quedar en manos de en un grupo social o sector predeterminado (gobernantes, legisladores, jueces, actores e interlocutores sociales, organizaciones de empleadores o sindicatos, gestores de la seguridad social, etc.), ni tampoco, por razones de pertinencia ideológica debe recaer en un segmento académico específico (economistas, actuarios, sociólogos, médicos, administradores, contables o juristas); la interdisciplinariedad es un facto primordial para efectuar diagnósticos correctos e integrales que permitan formular propuestas viables y factibles de solución al analizarse este problema integralmente, siempre desde distintos ángulos y bajo diversas ópticas.

Porque si la seguridad social actual es fruto de siglos enteros de búsqueda de la anhelada protección en contra de las vicisitudes de la vida en sociedad en este mundo riesgoso que habitamos, entonces no hay excusa para trabajar armónicamente en equipo, sin prejuicios ni cargas ideológicas preconcebidas, tratando de adaptar este magnífico manto protector a las necesidades cambiantes del mundo actual y del mañana, con base en la experiencia obtenida en más de un siglo de operación de la seguridad social.

Debemos encontrar pronto el sentido y la genuina identidad contemporánea del servicio público de la seguridad social, entendiendo no sólo qué es, sino también para qué nos 
sirve o debería servirnos. Si el mundo laboral se ha trasformado tan drásticamente, ¿qué nos mueve a pensar que la seguridad social que le ha acompañado desde hace poco más de un siglo no ha cambiado o debe hacerlo para reinventarse?

Conste que no se trata sólo de definirle para encasillarle teóricamente para meros fines académicos; pese a todo, es probable es que la gente no sepa definir qué es la seguridad social, pero ciertamente sí que entiende para que le sirve, especialmente cuando disfruta de sus prestaciones. Al igual que sucede con el esquivo concepto de derechos humanos — y la seguridad social es uno de ellos, que conste-, mejor que definirle será entender qué es, terminando así con las confusiones en esta "Torre de Babel" en que se ha convertido la seguridad social actual de un tiempo a la fecha.

Es verdad que alrededor de la seguridad social hay demasiados intereses en juego, pero el espinoso tema de la sostenibilidad debe ser prioritario; si no es financiable este servicio público, corre el riesgo de desaparecer. Por ello la necesidad de redefinirle a fin de poder reconstruirle conceptualmente primero, y luego, conforme a nuestras propias necesidades y posibilidades socioeconómicas reales, adecuarla de la mejor manera en nuestra normatividad nacional interna a partir del eje en el cual ineluctablemente debe gravitar siempre este magnífico manto protector: la solidaridad. Porque sin solidaridad no puede haber seguridad social posible... acaso habría alguna cosa — cualquier otra cosa, incluso una sofisticada mezcla que pudiese hasta parecérsele_- pero no existiría una genuina y auténtica seguridad social.

De manera pues que conviene encontrar pronto la identidad perdida al paso del tiempo de nuestra actual seguridad social, la que de suyo, siendo objetivos, muy poco tiene qué ver ya con los primarios seguros sociales "Bismarckianos" de finales del siglo XIX, pues los esquemas protectores ideados no son inmutables sino evolutivos en grado sumo conforme a las circunstancias del momento. Cierto, los seguros sociales son los "instrumentos" de que se sirve la seguridad social para intentar ser lo que debería ser — y que por desgracia no es todavía_-, y son a la vez su antecedente histórico, pero no más.

Ante la constante evolución y necesaria adaptación que ha sufrido por obvias razones la seguridad social tradicional a estas alturas — drásticos cambios que con mayor razón nos obligan a efectuar una nueva reconceptualización de este sistema protector por excelencia, se insiste-, debemos de reconocer que no sólo sus ideales y propósitos, sino sus resultados e impacto se han alejado demasiado de la entelequia del modelo "Beveridgeano" de 1942, e incluso de la llamada "Norma Mínima de Seguridad Social", contenida en el Convenio 102 de la OIT, que data de 1952.

Cada uno de tales antecedentes históricos precitados fueron diseñados y útiles en la vertebración de sistemas de seguros sociales funcionales en su tiempo, pero han 
dejado de ser realmente efectivos por razones multifactoriales al ser rebasados por las actuales circunstancias; por ello, los enormes problemas que resienten nuestros sistemas nacionales al haber transitado de los primarios seguros sociales a la seguridad social contemporánea, demuestran que éstos requieren con urgencia de ajustes estructurales inteligentes para adecuarse a las actuales circunstancias del mundo del siglo XXI. La regla de oro de la administración de todo seguro es que no se cambie lo que funciona bien, pero que se cambie lo que ya no funciona. Así de simple.

Por lo demás, se percibe además de un palpable deterioro en los sistemas de protección social instrumentados, un abierto e injustificado abandono del Estado como garante y responsable que es de éste servicio público, acaso al haber perdido de vista el que la seguridad social no es un gasto sino una inversión en lo mejor que tiene un pueblo, que es su gente.

Asimismo, los drásticos golpes de timón resentidos en los modelos de que se sirve la seguridad social digamos que tradicional, junto a la tardanza en el reconocimiento de problemas estructurales en el diseño de los seguros sociales sin pasar desapercibido el manipuleo político de que ha sido objeto de unos años a la fecha-, le han borrado a la seguridad social su careta y fisonomía habitual hasta el grado de volverle ahora prácticamente irreconocible a quienes le hemos venido observando de cerca desde hace ya muchos años.

Se ha dicho insistentemente que la seguridad social futura es ya financieramente inviable, aunque no siempre una mentira repetida mil veces se vuelve verdad. Empero, la tesis netamente economicista de su eventual infinanciabilidad futura es sólo una falacia; dinero siempre habrán para financiar la seguridad social, por más limitada que sea la economía de cualquier país, siempre a condición de que el "factor político" - que es clave en la toma de decisiones en este tipo de asuntos sociales de gran envergadura-, esté dispuesto a jerarquizar y priorizar sus objetivos a mediano y largo plazos.

No obstante, más allá de lo que haga cada país al respecto, lo cierto es que compete a los organismos mundiales como la AISS el delinear políticas y programas generales congruentes con la realidad actual, que sienten las bases de las tendencias actuales de impacto internacional y las prioridades en las tareas a acometer en este delicado rubro tan incomprendido como ignorado.

Ésta es, en síntesis, la actual encrucijada existencial de la seguridad social contemporánea: dilucidar qué es, cómo se estructura, para qué sirve, cómo debe operar, a quiénes debe proteger, y de qué manera debe ser financiada.

Por cierto, como el asunto de dilucidarlo es un reto enorme y el problema es de todos sin distingo de raza, sexo o credo, a todos nos toca asumir responsabilidades 
ante lo colosal del desafío. A fin de cuentas el problema es global y lo sepamos o no, lo entendamos o no, de alguna manera todos los habitantes de un país directa o indirectamente terminamos aportando y contribuyendo con nuestros impuestos al sostenimiento de los sistemas de seguridad social nacionales. ¡Pues eso!

\section{La financiación de la seguridad social del futuro}

Respecto de la sostenibilidad y consiguiente financiación de la seguridad social, ¿cuál es la mejor manera de costear este servicio público en un mundo de desempleo abierto?, un servicio público que teóricamente es un redistribuidor del ingreso nacional, un instrumento del desarrollo económico y social sostenible, y una herramienta efectiva de las políticas nacionales en épocas de crisis como la que ahora atraviesa el planeta. Desde luego que la pregunta es simple, pero la respuesta es bastante compleja. Veamos porqué.

La sostenibilidad de la seguridad social es un asunto medular dentro de la problemática general que afronta cualquier nación, junto a los embates que interesadamente resiente dicho servicio público por quienes buscan su eventual desaparición —asunto éste demostrable ante el desmantelamiento sistemático del que ha sido objeto en algunos países, sobre todo Latinoamericanos-. Importa destacar que éste asunto de la sostenibilidad presente y futura de este servicio público, forma parte del compromiso de la AISS por alcanzar una seguridad social dinámica y seguir el camino vital de su progreso, — una temática abordada también en el "Foro Mundial de la Seguridad Social" de Moscú, en septiembre de 2007-. De manera pues que el tema financiero es de enorme trascendencia.

Por caro que pueda parecer este servicio público, lo cierto es que vale mucho más de lo que cuesta. Tradicionalmente se efectúa su financiamiento de muy diversas maneras, acorde a las prioridades de protección y las posibilidades socio-económicas de cada nación. Aún a riesgo de caer en reduccionismos o generalizaciones peligrosas, tratando de focalizar adecuadamente el tema diremos que las principales fuentes de ingreso para costar la seguridad social son 4, a saber:

a) Las cotizaciones de los empleadores y trabajadores como principales recipiendarios del servicio — que no los únicos, que conste-, junto con los aportes efectuados a manera de contraprestación por quienes se benefician de manera directa de este servicio;

b) Las aportaciones públicas del Estado, recaudados ya sea mediante impuestos con afectación específica o no, o bien al través de subsidios fiscales, efectuados periódicamente y en ambos casos prevenientes del erario, 
destinados como es lógico suponer al llamado "gasto público social";

c) Los rendimientos obtenidos de las inversiones de los activos financieros del seguro social operador del mismo — salvo desde luego en los modelos de capitalización individual, por obvias razones-; y,

d) Los gastos privados directos, tales como las primas de seguro, los ahorros voluntarios para pensiones, los gastos directos en el rubro de salud, etc.

En este punto, experiencias de países exitosos con sistemas de seguridad social sólidos, demuestran que más que el propio modelo adoptado o los pilares en que se sustente el sistema, reviste capital importancia la correcta elección de los mecanismos de su financiamiento. De manera muy simple diremos que en cuanto atañe al aspecto meramente prestacional, los niveles en que suele brindarse el servicio público de la seguridad social contemporánea —y en cierto modo costearse—, es el siguiente, elementalmente explicado para su comprensión propedéutica:

- Un primer nivel, público, general, de tipo asistencial, que es financiado vía impuestos. Podríamos decir que es algo así como un "primer escalón de acceso" a la seguridad social, también conocido como la asistencia social de la seguridad social;

- Un segundo nivel, también público aunque éste es específico y obligatorio, típico del tradicional modelo de reparto o fondo común solidario, costeado mediante "cuotas" ó aportes de seguridad social de índole tripartito (a cargo de empleadores, operarios y el Estado), inexorablemente ligados al empleo formal o regulado, y sin perjuicio de extenderlo a otros grupos sociales productivos que el Estado considera proteger; y,

- Un tercer nivel, complementario, generalmente de índole voluntario aunque en algunos países es obligatorio, al través de pagos privados directos o ahorros efectuados a los fondos de retiro y/o pensiones con administración privada, para adquirir el asegurado su propia pensión llegado el retiro.

Esto se ha hecho generalmente así a lo largo de la historia, pero pensamos que no debe seguir costeándose de esta manera. La mejor forma de financiar este servicio público en el futuro, es "deslaboralizando" la seguridad social en un mundo de abierto desempleo. Así, por un lado ya no seguirá atada al trabajo formal, ahora en franca decadencia, con objeto de que no se afecten más las finanzas de las instituciones operadoras como consecuencia inmediata y directa de tan sentida realidad mundial - misma que no es factible modificar por simple decreto-; y, por el otro lado, tratando de alcanzar su verdadera universalización, cabría proponer ahora que en vez. del pago de aportaciones especiales a la seguridad social, de índole tripartita y que impactan 
en la nómina de las empresas en épocas difíciles, conviene costear este servicio público vía impuestos generales, en una franca y abierta solidaridad social de todos — así sea ésta forzada—, se esté o no vinculado a una relación de trabajo subordinado.

Bajo esta nueva política socioeconómica, la idea de fondo es que paguen más impuestos destinados a costear la seguridad social quienes más ingresos tengan, y en su caso que queden exentos de hacerlo quienes carezcan de ingresos qué gravar.

Esto haría que toda la colectividad, quien a fin de cuentas es directa o indirectamente beneficiada por la operación de dicho sistema protector —esté o no asegurada-, mediante su aportación impositiva pre etiquetada ex profeso para financiar la seguridad social nacional, sabrá lo mucho que cuesta cubrir este servicio público pero también lo mucho que le sirve, apreciándolo de mejor manera y coadyuvando a cuidarlo al valorarlo a plenitud. Porque lo que no cuesta suele no ser valorado.

Proponer solventar el coste de la seguridad social nacional vía impositiva exclusivamente no es una idea nueva; a partir de Inglaterra son muchos los países que ya lo hacen al destinar una parte de sus ingresos fiscales para ello. Sin embrago, lo que sí es novedoso es la idea de abandonar la rebasada idea de continuar costeándolo mediante aportaciones de seguridad social ligadas a la nómina — y por ende atarle sin razón al empleo formal—. Si el derecho humano al acceso a la seguridad social es de todos, más allá de su quehacer habitual o productividad mostrada, entonces que se universalice este servicio público pero que a su vez todos paguen impuestos para financiarlo, respetando siempre el trato jurídicamente diferenciado a que propende el Derecho Social intentando igualar los desniveles naturales de los segures humanos bajo la premisa de darle más al quien más necesita, menos al que necesita menos, y nada al que afortunadamente nada necesita. Esta es la mejor expresión de la seguridad social.

Desdeluego nos esperanza que éstas ideas, debidamente meditadas y reelaboradas, puedan dar origen luego a un Programa especifico por parte de la AISS, en el cual se sugiera a todos los países u organizaciones a ella adheridos, exploren con objetividad y sin prejuicios la vía impositiva directa intentando unificar criterios internacionalmente, no sólo en el aspecto prestacional de la seguridad social, sino también los criterios de financiamiento que es, sin duda, el mayor problema de los países del planeta. ¿Qué existe una mejor probada manera de financiar la seguridad social? Pues entonces, con toda la información debidamente procesada de que dispone la AISS tras operar con eficiencia desde 1927, que lo diga con claridad y ya está, porque se trata de convencer, no de vencer. Los Estados y los propios gestores de la seguridad social lo que requieren es información confiable y actualizada para una mejor toma de decisiones. Decirlo, comentarlo, sugerirlo, no implica imposición, y sin embargo 
una buena idea sobre la cual trabajar responsablemente en un tema tan polémico como éste siempre será bienvenida.

Por lo demás, contrario a lo que podría suponerse, la propuesta aquí efectuada acerca de cubrir exclusivamente el ingente coste de la seguridad social vía impuestos no intenta aumentar el elenco de tributos nacionales, sino apunta sólo a sustituir a la obligación contributiva ya existente (las clásicas aportaciones de seguridad social ligadas a la nómina), mediante el pago de impuestos generales para que, se esté o no en relación de dependencia laboral, destinar esta recaudación específicamente a financiar la seguridad social nacional, un servicio público que es de todos y para todos, no sólo de los trabajadores subordinados como prejuiciosamente se argumenta por sus más acervos críticos.

Los beneficios implícitos que traería aparejado sustituir la obsoleta forma de costar la seguridad social — los aportes ligados al empleo formal—, sustituyéndole por otro tributo que bien puede ser directo o indirecto, e incluso podría ir ligado a los impuestos sobre la renta o al consumo ya existentes en el país, obligarían a una nueva forma de entender este gasto público con sentido social, al destinarse un porcentaje predeterminado para sostener — y de ser posible, incrementar - los servicios o prestaciones que otorga la seguridad social instrumentada en el país, acorde siempre a las posibilidades económicas, culturales e idiosincrasia de éste. De tal manera que cada país decidiría soberanamente si para recaudar tales tributos utiliza impuestos pre existentes, o bien diseña un nuevo impuesto específico que sustituya a las cuotas obrero-empresariales ligadas a la nómina.

De esta manera el salario del trabajador subordinado será recibido por él integramente, sin retenciones ni descuentos para la seguridad social, un servicio público que seguiría disfrutando; empero, al ahorrarse el pago de aportes el empresario, le quedará un margen mayor de ganancia mayor y tomará mejores decisiones respecto a la operación de su empresa. Esto automáticamente aumentaría la capacidad de consumo de bienes y de servicios, alentando un círculo virtuoso al fomentar el empleo formal y desalentando el uso de sofisticadas figuras jurídicas que buscan evadir el pago de aportes a la seguridad social nominal ante lo elevado de su coste, evitándose la creación de empleo precario de mala calidad. $\mathrm{Y}$ al final del ciclo económicoproductivo, al no impactar el coste de la seguridad social en las nóminas, los bienes y servicios producidos tendrían precios más competitivos, ampliándose el margen de utilidad empresarial, pues su coste llega a representar hasta la cuarta parte del salario diario de un empleado subordinado.

Así las cosas, el tema financiero de cualquier sistema de seguridad social es clave en su desarrollo e impacto colectivo, desde luego junto con los asuntos relativos a la gestión eficiente, políticas de racionalización del gasto, reordenación de prestaciones y reequilibrio de las cargas del sistema. 
Insistimos que en vez de gravarse las nóminas, el sentido común dicta que debe atenderse a la riqueza real del contribuyente, donde quiera que éste se encuentre, siempre a partir de la solidaridad social y respetando en todo caso los principios de equidad y la proporcionalidad tributarias en el pago del impuesto para la seguridad social que se propone implementar a nivel mundial.

Por lo demás, cualquiera que fuese su coste real, jamás se debería confundir el valor con el precio de las cosas, pues el valor de la seguridad social es sencillamente inconmensurable. Recordemos aquí — por si alguna duda quedase a éste respecto-, la célebre frase que nos legara Otto Von Bismarck, creador del primer seguro social del planeta, al defender su proyecto cumbre ante el Parlamento alemán hacia finales del siglo XIX: "Por caro que parezca el seguro social resulta menos gravoso que los riesgos de una revolución”. Mejor dicho, imposible.

La educación previsional jugará en todo esto un rol protagónico estelar. La idea central es que todos, gobernantes y gobernados entiendan de qué se trata este complejo asunto de la seguridad social contemporánea y futura, de manera tal que se impidan los errores estructurales del sistema y que, de haberlos, de toda buena fe sean detectados y corregidos de inmediato dichas falencias.

Porque los resultados de esta ancestral ignorancia e indiferencia han provocado que se hagan las cosas exactamente al revés a como la lógica imponía hacerlas, pues en vez de que la economía nacional sirva a la seguridad social coadyuvando a financiarle y a fortalecerle, han sido las mermadas finanzas de la seguridad social las que sirven para fortalecer la economía nacional; esto es por desgracia lo que ha ocurrido en muchos de los países de América Latina, así los discursos oficialistas intenten ocultar el problema de fondo negándose a reconocerlo. En este punto, la ausencia de valores de todo tipo — entre ellos la solidaridad social, hoy abiertamente cuestionada por grandes sectores productivos de una manera sospechosamente interesada-, nos pasa factura como sociedad organizada.

Precisamente por eso no es de extrañar el que la seguridad social sea algo de lo más inseguro que existe en este mundo riesgoso en que habitamos; más temprano que tarde pagaremos todos los altísimos precios del total abandono en que hemos tenido a la seguridad, quien en simple reciprocidad nos abandona ahora.

Hoy es un momento propicio para iniciar esta colosal tarea propuesta, pues las crisis son también espacios generadores de oportunidades; aprovechémoslo, pues la actual crisis económica y financiera global habrá de cambiar drásticamente las reglas económicas del juego productivo-laboral y hasta la actividad financiera mundial, cambiando de manos la riqueza y los grupos que otrora manejaban las finanzas y el comercio mundial. Porque tras ésta dolorosa sacudida global, el mundo nunca 
volverá a ser igual que antes, y entonces, si no es factible cambiar al mundo, entonces cambiemos nosotros para adaptarnos mejor a nuestro entorno y circunstancias actuales como la sociedad organizada que nos preciamos de ser. De ello dependerá en gran medida nuestro inquietante futuro.

\section{Propuestas básicas acerca del tema abordado}

Con base en lo razonado, nos es posible formular enseguida algunas ideas, conclusiones y Propuestas básicas:

PRIMERA.- Las nuevas formasproductivas junto a la penosa situación de desempleo mundial nos obliga a pensar ya en reconceptualizar, en la segunda década del siglo XXI, qué es y para qué deben servir los sistemas nacionales de seguridad social, considerando a este servicio público como lo que en realidad es: un derecho fundamental de la persona humana que es al cargo de Estado, acorde a lo estatuido por el artículo 22 y descrito con precisión en el artículo 25 de la "Declaración Universal de los Derechos Humanos" de la Organización de las Naciones Unidas, del 10 de diciembre de 1948.

La reconceptualización de la seguridad social contemporánea es un tema clave en todo el proceso de renovación que requiere este servicio público que, al menos por ahora, adolece de una identidad propia y perfectamente definida; lo que se busca es la evolución plena de la seguridad social en el complejo mundo actual, un sistema que no sea confundido conceptualmente con otras figuras jurídicas parecidas — que no iguales-, tales como: "protección social”, "asistencia social”, "previsión social laboral”, y otras análogas, cuyas fronteras son en la práctica más móviles de lo que podríamos suponer desde la simple teoría jurídico-social, sistemas protectores que suelen ser manipuladas políticamente a capricho del legislador o del gobernante en turno.

SEGUNDA.- Por lo tanto, habrá qué efectuar también una exhaustiva reconceptualización de la protección social genérica — de la cual forman parte todas las figuras jurídicas pre referidas-, para dimensionarlas y acotarlas, buscándose siempre su genuina identidad propia porque cada una de ellas tiene orígenes, propósitos, alcances y medios de financiación distintos, por lo cual son perfectamente diferenciables la una de la otra.

La enorme confusión conceptual provocada por la laxitud conceptual generada por falta de una adecuada ortodoxia jurídica, es aprovechada por muchos para "manipular" la seguridad social nacional, entremezclando ya por ignorancia o ya mala fe (a veces por ambas cosas) las distintas especies que integran la protección social genérica reconocida por la OIT, haciéndolo a conveniencia y generando a la larga un caos de figuras jurídicas que, insistimos en ello, son perfectamente definibles, 
hasta volverles un galimatías complicadísimo de interpretar y resolver en la práctica incluso hasta para la propia AISS, en esta peculiar "Torre de Babel" en que hemos convertido a la seguridad social, donde pensamos que hablamos de lo mismo pero no nos entendemos. Opinamos muy respetuosamente que no toda la protección social es seguridad social, como se nos ha hecho creer; porque la seguridad social forma parte de la protección social y no al revés. Atrevámonos a reconocerlo y a decirlo públicamente para no volver a extraviar el camino.

TERCERA.- En reciprocidad al derecho humano inalienable de disfrutar del manto protector de la seguridad social, por razones de elemental congruencia habrá qué pensar también en las renovadas obligaciones del Estado con respecto de este servicio público fundamental, con la finalidad de que éste asuma su rol de garante, regulador y responsable final que le corresponde, teniendo en mente un objetivo perfectamente definido: que la seguridad social no deje de ser un derecho social exigible al Estado vía jurisdiccional, en caso de resultar necesario — más allá de que en su gestión intervengan empresas privadas con fines de lucro, pero sin que la participación de éstas le cueste a los recipiendarios del servicio_- Lo público y lo privado pueden coexistir armónicamente a condición de que la gestión se encuentre correctamente regulada en la normatividad legal aplicable.

De manera pues la figura jurídica de la subrogación administrativa en tareas específicas de seguridad social, será válida a partir de una única premisa: si el servicio brindado a los recipiendarios es satisfactorio, que se continúen delegando atribuciones específicas a las empresas privadas participantes en la gestión de la seguridad social; pero si no lo es, entonces quien debe responder siempre ante el ciudadano afectado debe ser el propio Estado, pues éste podrá repetir luego o exigir el cumplimiento cabal de obligaciones a la empresa subrogada omisa e incumplida.

CUARTA.- En tanto que para la persona humana la seguridad social es un derecho humano irrenunciable, inalienable e inextinguible, para el Estado debe ser un servicio público originariamente a su cargo — ya que por cada derecho debe haber un sujeto obligado a satisfacerlo-, y de cuya prestación en ningún caso podrá excusarse. Importa y mucho el que la ciudadanía confíe en un servicio público que esté correctamente planificado y debidamente estructurado; un servicio público que sea trasparente y rinda cuentas claras de su gestión; un sistema protector planeado para operar a mediano y largo plazos, que no esté sujeto a los vaivenes políticos y, por sobre todas las cosas: que no cambie las "reglas del juego" durante el juego por más duras que sean las crisis económicas — variantes e imponderables éstos que también pueden y deben ser previstos por cada país_- Hablamos aquí de responsabilidad y de credibilidad, dos aspectos trascendentes que hoy en día, siendo francos, la ciudadanía pone en duda 
En este último punto, le importa al gobernado que se vuelva efectiva la figura jurídica de la latencia de derechos — esto es, que se respeten los derechos latentes del asegurado en proceso de consumación-, dejándose atrás la idea de simples "expectativas de derechos" (sic) no configurados todavía, como por desgracia se ha venido manejando este delicado tema en agravio de millones de personas a quienes sus pensiones le son reducidas y/o congeladas, o los servicios médicos institucionales le son negados condicionándolos al co-pago. Estas nuevas reglas que operen en todo caso para los nuevos asegurados que se incorporen al sistema, más no a los que ya estaban incorporados, a quienes les agravia la aplicación retroactiva de la legislación que modifica los requisitos de acceso a prestaciones de seguridad social. Esto en verdad que no se vale.

QUINTA.- Este servicio público vital, de innegable impacto social y económico, debe blindar antes que todo su viabilidad financiera presente y futura, financiándose de la mejor manera posible siempre mediante la indispensable solidaridad social — sin la cual no puede haber seguridad social posible_- El tema de su sostenibilidad es un asunto crucial que compete al Estado resolver al través de ideas claras y concisas que además sean viables y factibles de implementar en la práctica. Ya se sabe que en materia de seguridad social si el Estado no puede entonces nadie puede, como también se sabe que el reconocimiento del derecho es el valor de su garantía.

Así las cosas, considerando que ante las circunstancias actuales ya no es pertinente seguir atando la sostenibilidad futura de este servicio público al empleo formal o regulado, debido a que el desempleo socava sin remedio las finanzas de las instituciones de seguridad social, la idea de fondo es tratar de universalizar el manto protector de la seguridad social —aunque sea en los servicios más básicos, como lo son salud y pensiones-, pensándose en nuevas formas de sufragar su ingente coste, por ejemplo sustituyendo con eficacia a los obsoletos "aportes de seguridad social" que por diversos factores han dio rebasados por la realidad y en la práctica ya no funcionan como es debido.

SEXTA.- Una idea ya probada con éxito en la creación de nuevos mecanismos generales de financiamiento lo son los impuestos. El punto medular de esta Ponencia es precisamente éste álgido tema, y por pertinencia metodológica, en obvio de repeticiones damos aquí por reproducidos los argumentos vertidos en párrafos precedentes como si se insertasen a la letra.

La manera más sencilla de hacerlo será costear la seguridad social vía impuestos generales, alcanzándose varios fines distintos a la vez: a) una responsabilidad indeclinable del Estado en su prestación y un efectivo control; b) una seguridad social nacional que sea factible, viable, positiva, pero sobre todo segura y confiable; $y, c)$ una solidaridad social general que es indispensable en los tiempos actuales, más allá de si se tiene 
o no empleo, pues en todo caso el pago de impuestos que sostienen al Estado — esto es, a sus estructuras e instituciones_- es una obligación básica de toda la ciudadanía. La idea impositiva planteada no olvida preservar la plena observancia de los principios de la equidad y proporcionalidad fiscales, gravándose en vez de la nómina, la riqueza real de las personas físicas y/o jurídicas.

SÉPTIMA.- Finalmente, la grave situación financiera que afronta la seguridad social contemporánea obliga también al compromiso de toda la ciudadanía y al establecimiento consensuado de una política nacional de largo alcance, planeada democráticamente y sin ideologizaciones de ninguna índole para que pueda ser respetada a largo plazo, sin que incidan o lo impidan los problemas o la alternancia política, estableciéndose los tramos de responsabilidades de cada quién en forma tal que nadie quede excluido del rumbo que tomará este asunto a futuro, un servicio público esencial para cualquier país.

Ello supondría una toma de conciencia nacional para que cada uno de nosotros pongamos manos a la obra en los quehaceres que nos competen, si bien la idea gira en torno a que a nivel Constitucional exista en cada país una normatividad legal especifica que, por un lado vuelva un derecho social exigible a la seguridad social y, por el otro, determine responsabilidades por acción u omisión de quienes incumplan con sus tareas, sean legisladores, funcionarios públicos, impartidores de justicia, o simples ciudadanos. 